\title{
Contributions to biodiversity theory: the importance of formal rigor
}

\author{
L. Contoli ${ }^{1}$ and L. Luiselli ${ }^{2,3}$ \\ 1 private address: Via Arno 38, 00198 Rome, Italy \\ ${ }^{2}$ Niger Delta Ecology and Biodiversity Conservation Unit, Department of Applied and Environmental Biology, \\ Rivers State University of Science and Technology, PMB 5080, Port Harcourt, Rivers State, Nigeria \\ ${ }^{3}$ IDECC - Institute for Development, Ecology, Conservation and Cooperation, via G. Tomasi di \\ Lampedusa 33, 00144 Rome, Italy \\ Correspondence to: L. Luiselli (lucamlu@tin.it)
}

Received: 24 September 2015 - Revised: 24 October 2015 - Accepted: 27 October 2015 - Published: 9 November 2015

\begin{abstract}
In this short paper, some consideration is given to the term biodiversity. We stress the need for a strong formal rigor in using this term in order to maintain the credibility by non-ecologists and environmental agencies over the scientific community involved in biodiversity studies. After a historical introduction to the use and concept of the term biodiversity, this paper presents some theoretical aspects, concrete methodological proposal, and discussion for the further scientific and consistent use of the term biodiversity.
\end{abstract}

\section{Historical introduction}

Authors of ecological papers have used the term biodiversity with various meanings over the decades. The phenomenon of biodiversity has been analytically described in practice, without any exact conceptualization, since the classical authors (see, e.g., Lucretius, $54 \mathrm{BC}$ ) up to the origin of ecology as a science, in the second half of AD 800. According to Pignatti (2006), the word biodiversity probably took its origin from the Italian scientist Federico Cesi (1651), who coined diversitas plantarum (Latin: i.e., the diversity of plants), the "diversity of the elementary units of the whole set of the plants". It is remarkable that Cesi (1651) wrote explicitly about diversitas (diversity) rather than differentia (difference), because the term differentia would refer to a comparison between different sets (Pignatti, 2006).

For the expression biological diversity (see Dasmann, 1968) and the derived term biodiversity (Rosen, 1985; Wilson, 1988), several definitions were proposed:

1. Each kind of variability among living organisms and its ecological complex, as established by the Rio Conference on Sustainable Development in 1992, apparently cumulate discrete and continuous variability.
2. The totality of genes, species, and ecosystems of a region (Larsson, 2001) is quite restricted to some territorial abundance.

3. The variation of life at all levels of biological organization (Spicer, 2004) cumulates variance and diversity.

In the first half of the twentieth century, a better theoretical approach to the concept of biodiversity arose through the use of mathematical tools (Gini, 1912; Shannon and Weaver, 1948; Simpson, 1949) along the way of the science of multiplicity-complexity, at least partly arising from the roots of thermodynamics. However, the physical meaning of biodiversity, linked to the statistical multiplicity and complexity, was rarely underlined by authors.

Some further quantitative research, theoretically very promising and valuable (e.g., Patil and Taillie, 1976; Pielou, 1975; Hill, 1973; Magurran, 1988, 2004; Magurran and McGill, 2011), was a bit overlooked, while there was a illusory race towards discovering the best index (see also the critiques presented by, e.g., Margalef, 1957, 1986; Barbault et al., 1991; Colwell, 1979; and in general Dhand and Howlett, 2000). During the increasing environmental crisis of the last century, there was a pressing impetus towards operative and pragmatic solutions (especially after the Rio Conference in 
Table 1. Google Scholar analysis of the occurrence of the following terms in the ecological literature: B - biodiversity; B - biodiversity, abundance, numerosity, richness, evenness, and profiles. The abbreviation o.o.m indicates order of magnitude.

\begin{tabular}{llrll}
\hline Year & B & B & B/B & B/B (o.o.m.) \\
\hline 1940 & 5 & 5 & 1 & 1 \\
1945 & 22 & 7 & 0.3 & 0 \\
1950 & 6 & 6 & 1 & 1 \\
1955 & 5 & 5 & 1 & 1 \\
1960 & 8 & 8 & 1 & 1 \\
1965 & 3 & 3 & 1 & 1 \\
1970 & 69 & 54 & 0.8 & 1 \\
1975 & 5 & 5 & 1 & 1 \\
1980 & 124 & 55 & 0.4 & 0.5 \\
1985 & 384 & 52 & 0.1 & 0.5 \\
1990 & 522 & 57 & 0.1 & 0.5 \\
1995 & 4310 & 54 & 0.01 & 0.3 \\
2000 & 8160 & 9 & 0.001 & 0 \\
2005 & 9570 & 7 & 0.001 & 0 \\
2010 & 543000 & 5 & 0.00001 & 0 \\
\hline
\end{tabular}

1992), and as a consequence the theoretical grounds of biodiversity were disregarded, even in the few acclaimed contributions (e.g., Eldredge, 2004; Wilson, 1999). Biodiversity and its protection were increasingly intended in a relatively static and non-evolutive sense. A quick analysis of Google Scholar shows that the term biodiversity increased exponentially from 1940 to 2010 (Table 1), whereas the entries for the more specific words such as abundance, numerosity, richness, evenness, and profiles declined, thus meaning that a more technical approach to the matter seems to have been becoming less common in recent years (Table 1) likely due to a declining interest in the conceptual aspects of such problems with respect to the emotional ones.

Nowadays, in the various definitions of biodiversity there is usually no emphasis on its functional aspects, and the term is even non-technically used as a synonym for nature or wilderness. Even studies allegedly more interested in the formal aspects aim at expressing diversity intuitively (Sherwin, 2010). So, it seems that some dubious use of the word biodiversity is present not only in non-scientific media but also within the scientific community.

In this paper, we try to reaffirm the need for applying methodological rigor in the field, presenting and discussing the conceptual unifying aspects of biodiversity, their names and definitions, because even an uncritical approach may favor the introduction of involuntary artifacts.

\section{Theoretical aspects, concrete methodological proposal, and discussion}

- Definition: biodiversity, the diversity of life, is the multiplicity, variety and interaction of each set of living systems (e.g., communities, guilds).

- Application field: a single, distinct set of living systems.

In several instances, the idea of biodiversity seems to be more relative to intuitive feeling rather than to perception, and even less to the field of the rational understanding. All our conceptions about biodiversity seem to refer essentially to our own spatial and temporal environmental context. Thus, at the end of the day, we have an intuitive idea of the word biodiversity, referring to biotic complexity. We are hence confronted with a personal concept that is intrinsically unique, exactly like the concept of environment. Therefore, we could provocatively combine the two terms into a single, further, subjective definition of biodiversity, a set inclusive of all the biotic interactions of each living system in a perceptive environment. Hence, each of us as living organisms would have a different perception of the exact meaning of the word biodiversity, and because of this we may end up with vague, ambiguous, and partly controversial definitions of this word. This may be linked to the well-known and never forgotten critique by Hurlbert (1971), who considered species diversity as a non-concept: at the very least biodiversity is not a mono-concept, but a multi-concept. This is understandable if we think that each mathematical index of biodiversity may correspond to a particular mathematical idea, although it is necessary to still respect the formal and unifying aspects of the concept clusters. This is necessary to guarantee that biodiversity will keep a purely scientific meaning, predominating over the social or political ones.

Moving from a more subjective to a more objective meaning of the term biodiversity, one goes from extrinsic to intrinsic approaches to it, ranging from aspects exclusively descriptive (extrinsic biodiversity) to those aspects that are functional and therefore intrinsic to the considered set. In most cases, studies deal with extrinsic properties of biodiversity (for instance, most of the current field studies on biodiversity), but the number of studies dealing with intrinsic properties of biodiversity is increasing year by year (see studies with mathematical modeling, like rarefaction, geometric, log-normal, logarithmic, and broken stick: see Magurran, 1988; Ganis, 1991).

Extrinsic biodiversity may be therefore only subjective and descriptive, thus avoiding concept systematizations. In general, biodiversity, unlike variance, is a quali-quantitative concept, apart from the particular case of a set composed by only one group. Biodiversity is different from difference in that biodiversity applies to a single set of typically discrete and distinct elements (Hamilton, 2005).

Biodiversity may have a meaning relative to the biological complexity (see, Paine, 1966; Odum, 1973; Pimm, 1982; 
Margalef, 1989; Contoli, 1992). Especially in this field and before any further speculation/analysis, it is always necessary to test the homogeneity of the samples as a mathematical set. This approach has already been performed (e.g., Contoli, 1998; Akani et al., 1999), but in too many cases this is regularly forgotten by experimenters (e.g., see Contoli, 1998, for a discussion).

On the other hand, intrinsic biodiversity must be characterized by a objective typological systematization, according to the various elements, levels, scales, and components. Elements of biodiversity are the quali-quantitative set of application, the discrete and distinct subsets of the set, and the discrete and distinct elements of the subsets. We recommend that one not use terms with a previous particular meaning (e.g., in taxonomy). So, group for the subsets and unity for an element of the set seems to meet such a requirement.

- Set of application: all and only the groups and unities of the biological systems under study. The individuation of the set is fundamental, especially in the choice between a formalistic or relational approach. Namely, in comparisons among biodiversities of the same biotope in time, a stress can "open" a quite functionally isolated set towards some others that are much larger (Contoli, 1992), making the two sets noncomparable.

- Group: a discrete and separate part of the set, composed of one or more unities.

Linking biodiversity to a discrete quantitative concept and its definition, the group concept gives a quali-quantitative meaning to biodiversity. Nevertheless, even a series of continue values can be subject to diversity indices through, for example, a multivariate tool, like principal component analysis.

- Unity: a discrete element of a group. The unity defines the level of the biodiversity.

- Numerical components: essential tools for each quantitative evaluation of biodiversity, the numerical components can be compared, for example, through diagrams called profiles (Reyni, 1961; Patil and Taillie, 1976) or in the frame of a evenness/richness graphic analysis of biodiversity (see, e.g., Contoli, 1986). Indeed, a large number of graphical analyses of diversity are available (Whittaker plots and diversity/dominance diagrams, ABC curves, k-dominance plots, richness/evenness diagrams; see Ukmar et al., 2007; Battisti et al., 2008).

- Abundance: number of unities in a set. The sample abundance is not only of numerical significance; it is also a necessary and fundamental, even if not sufficient, condition for biological diversification.

- Numerosity: number of groups in a set. It is the most widespread numerical approach to biodiversity. It must be mentioned that the concepts (and metrics) of abundance and numerosity have been often equivocated.

- Richness: a numerosity directly or indirectly weighted against abundance. The richness aims at making two or more numerosities comparable, through weighting (e.g., by rarefaction) if suitable (Contoli and Marenzi, 1982; Contoli, 1995).

- Evenness (e.g., equitability): degree of quantitative similarity of unity number among groups. Evenness is certainly the more important univariate metric of diversity that is sensitive to changes in species assemblages induced by anthropogenic and natural disturbances (Magurran and McGill, 2011). The evenness is often evaluated by detracting richness by a complex index of biodiversity. A relativization (Alatalo, 1981) or rarefaction (Contoli, 1995) procedure was adopted to purify evenness from other components of biodiversity, like richness.

- Dominance: prevalence numerical degree of one or few groups on the others of a set.

Biodiversity analysis can be applied to various dimensional and/or structural kinds of units, and indeed there are several typological levels:

1. molecular diversity (see Contoli, 1995; Campbell, 2003; e.g., different types of haemoglobin, chlorophyll, immuno-factors);

2. genetic diversity (e.g., allelic, genic, genomic; see Amori and Contoli, 1994; Mallet, 1996);

3. phenetic diversity (e.g., morphological or morphometrical characters; see, e.g., Amori and Contoli, 1994; Contoli, 1996);

4. biotic diversity in an ecological (i.e., ecospecies, sensu lato) or taxonomic meaning (through a number of sublevels; e.g., species richness, which is a very popular component of it);

5. community diversity (many measures - these metrics may be uni-, bi- and multivariate; see Magurran, 2004);

6. landscape diversity (many measures; e.g., ecosystem diversity);

7. Biodiversity analysis can be performed at different spatial (mainly, territorial) scales: this is clearly what has been shown by Whittaker (1977) and many later studies.

8. Punctual biodiversity; alpha-biodiversity; gammabiodiversity; and so on, up to a limit like: (limit-to-) $\rightarrow$ omega-diversity (at the biosphere scale; Contoli, 2007). They are defined as follows: 
a. alpha diversity: the diversity within a site, or quadrat, a.k.a. local diversity (Bacaro and Ricotta 2007);

b. beta diversity: the change in species composition from site to site, a.k.a. species turnover;

c. gamma diversity: the diversity of a landscape, or of all sites combined, a.k.a. regional diversity.

When we make comparisons among different levels of biodiversity (sensu Whittaker, 1977), it is always necessary to remember that odd ordinal numbers of the Greek alphabet (e.g., $\alpha, \gamma$ 1-3) correspond to true biodiversity, with the even letters $(\beta, \delta$, etc.) representing differences among different aspects of diversity.

- Indices of biodiversity: numerical tools to quantifying biodiversity. Diversity indices are a range of not fully inter-changeable tools that represent overall measures of diversity. Often, their aim is to weigh together, but differently, the various components of biodiversity (complex indices).

Some authors combined aspects of richness and evenness, but in different proportions, as can be seen through the $d i$ versity profiles (sensu Hill, 1973; Reyni, 1961; Patil and Tailie, 1976). The indices including the $\pi$ relative frequencies enable us to calculate the biodiversity of the principal components from continue measures. Note that the use of a widespread diversity index does not express at all, ipso facto, a biodiversity evaluation, if applied to inadequate data. So, the very popular Shannon-Wiener index $\left(H^{\prime}\right)$, of great international importance as it allows also some useful cumulative computations (e.g., in hierarchical biodiversity; see Feoli and Scimone, 1984), is unfortunately often used without adequate data sets.

\section{Conclusions}

In recent years, some instrumental critiques to the importance of defending biodiversity used as an argument the somewhat careless attitude in methods and analysis of most biodiversity research (e.g., see Lomborg, 2001). Apart from the instrumentality of these critiques, it would be necessary however in the future to avoid giving these weaknesses in the hands of those who act against environmental conservation as a whole.

If not correctly presented in both methodological and biological/functional terms, there is a real risk for the term biodiversity to be more deleterious than useful to the theoretical ecological knowledge and even to the more applied ecological science, with the ultimate result of being no more than a flatus vocis (Battisti and Contoli, 2011).
Acknowledgements. We are deeply indebted to C. Battisti and one anonymous referee for their careful reading of our manuscript and very interesting and useful suggestions.

Edited by: D. Montesinos

Reviewed by: C. Battisti and one anonymous referee

\section{References}

AA.VV.: Nature insight: Biodiversity, Nature, 405, 207-225, 2000.

Akani, G. C., Barieenee, I. F., Capizzi, D., and Luiselli, L.: Snake communities of moist forest and derived savanna sites of Nigeria: Biodiversity patterns and conservation priorities, Biodivers. and Conserv., 8, 629-642, 1999.

Alatalo, R. V.: Problems in the measurement of evenness in ecology, Oikos, 37, 199-204, 1981.

Amori, G. and Contoli, L.: Morphotypic, craniometric and genotypic diversification in Apodemus flavicolllis and Apodemus sylvaticus, Boll. Zool., 61, 353-357, 1994.

Bacaro, G. and Ricotta, C.: A spatially explicit measure of beta diversity, Community Ecol., 8, 41-46, 2007.

Barbault, R., Colwell, R. K., Dias, B., Hawksworth, D. L., Huston, M., Laserre, P., Stone, D., and Younès, T.: Conceptual Framework and Research Issues for Species Diversity at the Community Level, in: From Genes to Ecosystems, edited by: Solbrig, O. T., IUBS-SCOPE-UNESCO, Cambridge, MA, USA, 37-71, 1991.

Battisti, C. and Contoli, L.: Diversity Indices as "Magic" tools in landscape planning: a cautionary note on their uncritical use, Landscape Res., 36, 111-117, 2011.

Battisti, C., Ukmar, E., Luiselli, L., and Bologna, M. A.: Diversity/dominance diagrams show that fire disrupts the evenness in Mediterranean pinewood forest bird assemblages, Community Ecol., 9, 107-113, 2008.

Campbell, A.: Save those molecules: molecular biodiversity and life, J. Appl. Ecol., 40, 193-203, 2003.

Cesi, F.: Plantarum inter se diversitas, Tabulae phytosophicae, XVIIII, in: Thesaurus Mexicanus, 1651.

Colwell, R. K.: Toward a unified approach to the study of Species Diversity, in: Ecological Diversity in Theory and Practice, edited by: Grassle, J. F., Patil, G. P., Smith, W., and Taillie, C., International Cooperative Publishing House, Fairland, MD, USA, 7592, 1979.

Contoli, L.: Sulla diversità dei sistemi trofici "strigiformi - mammiferi" nel Parco del Circeo e relative valutazioni ambientali, Atti Conv. Asp. Faun. Probl. Zool. P. N. Circeo (Sabaudia, 1984): 169-181, 1986.

Contoli, L.: Ecological diversity and complexity in relation to the environmental quality, S.IT.E./Atti, 14, 11-21, 1992.

Contoli, L.: Sulla Diversità biotica come manifestazione ecologica dell'Entropia, Atti e Memorie, Ente Foreste Sicilia, 2, 23-86, 1995.

Contoli, L. : Sulle collezioni museali nello studio della biodiversità fenetica, Museologia scientifica, 13 (supplement), 51-59, 1996.

Contoli, L.: Biodiversità di specie: aspetti formali e funzionali, Atti dei Convegni Lincei, 143, 113-126, 1998.

Contoli, L. and Marenzi, A. R.: Una valutazione della diversità col metodo di rarefazione, applicata al sistema trofico "micromammiferi terragnoli - Tyto alba”, CNR, AQ/5/36, Roma, Italy, 1982. 
Dasmann, R. F.: A different kind of country, Macmillan, New York, USA, 1968.

Dhand, R. and Howlett, R.: Biodiversity, Nature Publishing Group, London, UK, 2000.

Eldredge, N.: La vita sulla Terra, Codice ed., Torino, Italy, 2004.

Feoli, E. and Scimone, M.: Hierarchical diversity: an application to broad-leaved woods of the Apennines, Giornale Botanico Italiano, 118, 1-15, 1984.

Ganis, P.: La diversità specifica nelle comunità ecologiche, GEADEQ no. 10, University of Trieste, Italy, 1991.

Gini, C.: Variabilità e mutabilità, Studi econ. giur., Univ. Cagliari, a. III / II, 1912.

Hamilton, A. J.: Species diversity or biodiversity?, J. Environ. Manage., 75, 89-92, 2005.

Hill, M. O.: Diversity and Evenness: an unifying notation and its consequences, Ecology, 54, 427-432, 1973.

Hurlbert, S.: The non-concept of species diversity: A critique and alternative parameters, Ecology, 52, 577-586, 1971.

Larsson, T. B.: Biodiversity evaluation tools for European forests, Wiley-Blackwell, New York, USA, p. 178, ISBN 978-87-1616434-6, 2001.

Lomborg, B.: The skeptical environmentalist - Measuring the Real State of the World, Cambridge University Press, Cambridge, UK, 2001.

Lucretius, T. C.: De rerum natura; II: 342-346, 54 BC.

Magurran, A. E.: Ecological diversity and its measurements, Chapman \& Hall, London, UK, 1988.

Magurran, A. E.: Measuring Biological diversity, Blackwell Science, New York, USA, 2004.

Magurran, A. E. and McGill, B. J.: Biological Diversity, Oxford University Press, Oxford, UK, 2011.

Mallet, J.: Biodiversity: A Biology of Numbes and Difference, edited by: Gaston, E. J., Blackwell Science, Oxford, UK, 13-53, 1996.

Margalef, R.: La teoria de la informacion en ecologìa, Mem. Real Acad. Cienc. Artes, Barcelona, Spain, 32, 373-449, 1957.

Margalef, R.: Ecologìa, Omega, Barcelona, Spain, 1986.
Margalef, R.: On diversity and connectivity, as historical expressions of ecosystems, Coenoses, 4, 121-126, 1989.

Odum, E. P.: Diversity as a function of energy flow, "Unifying concepts in Ecology", edited by: Van Dobben, W. H. and LoweMc Connell, R. H., Junk, The Hague, the Netherlands, 139-150, 1973.

Paine R. T.: Food web complexity and species diversity, Am. Nat., 100, 65-75, 1966.

Patil, G. P. and Taille, C.: Ecological diversity: concepts, indices and applications, in: Proceedings of the 9th Int. biometric conference, The Biometric Society, 2, 383-411, 1976.

Pielou, E. C.: Ecological Diversity, Wiley, New York, USA, 1975.

Pignatti, S.: Relazione introduttiva, Convegno Internazionale Diversitas e Biodiversità. Accademia nazionale Lincei, Univ. Perugia, Italy, 2006.

Pimm, S. L.: Food webs, Chapman \& Hall, London, UK, 1982.

Reyni, A.: On measure of entropy and information, in: "Proceedings of the 4th Berkeley Symposium on Mathematical statistic and Probability", edited by: Nejman, J., Un. California Press, Berkeley, USA, 547-561, 1961.

Shannon, E. C. and Weaver, W.: A mathematical theory of communication, Bell System. Tech. J., 27, 379-423 and 623-656, 1948.

Sherwin, W. B.: Entropy and information approaches to Genetic Diversity and its Expression: Genomic Geography, Entropy, 12, 1765-1798, 2010.

Simpson, E. H.: Measurement of diversity, Nature, 163, p. 688, 1949.

Spicer, K. J.: Biodiversity: an introduction, Blackwell, Chicago, USA, 2004

Ukmar, E., Battisti, C., Luiselli, L., and Bologna, M. A.: The effects of fire on communities, guilds and species of breeding birds in burnt and control pinewoods in central Italy, Biodivers. Conserv., 16, 3287-3300, 2007.

Whittaker, R.: Evolution of species diversity in land communities, Evol. Biol., 10, 1-67, 1977.

Wilson, E. O.: Biodiversity, Oxford Univ. Press, Oxford, UK, 1999. 